\title{
Perdagangan Bebas Produk Farmasi dan Alat Kesehatan serta Kesiapan Memenuhi Persyaratan Cetak Biru Masyarakat Ekonomi ASEAN
}

\author{
Free Trade in Pharmaceutical Products and Medical Devices as well as \\ Readiness to Meet the ASEAN Economic Community Blueprint Requirements
}

\author{
Lukman Prayitno, ${ }^{1 *}$ Max Joseph Herman ${ }^{2}$ \\ ${ }^{1}$ Pusat Penelitian dan Pengembangan Humaniora dan Manajemen Kesehatan, Jakarta, Indonesia \\ ${ }^{2}$ Pusat Penelitian dan Pengembangan Sumber Daya dan Pelayanan Kesehatan, Jakarta, Indonesia \\ *E-mail: yohaneslukman@gmail.com
}

Diterima: 10 Juli 2019

Direvisi: 11 November 2019

Disetujui: 3 Februari 2020

\begin{abstract}
Abstrak
Implementasi Masyarakat Ekonomi ASEAN (MEA) sebagai langkah strategis Pemerintah Indonesia berdampak terhadap globalisasi ekonomi. Oleh karena itu, dibutuhkan suatu studi tentang perdagangan bebas produk farmasi dan alat kesehatan (alkes) terutama kesiapan untuk memenuhi persyaratan cetak biru MEA. Penelitian ini menggunakan metode kualitatif dan kuantitatif. Data diperoleh dari hasil round table discussion (RTD) "Perdagangan Bebas Barang dan Jasa Kesehatan di ASEAN" yang melibatkan Kemenkes, Kemendag, dan BPOM. RTD bertujuan mendapatkan informasi kesiapan memenuhi cetak biru MEA. Data sekunder ekspor dan impor produk farmasi dan alat kesehatan diperoleh dari Kemendag. Hasil kajian menunjukkan antara tahun 2013 sampai 2017 terdapat 70-72 jenis produk yang diekspor ke 9 negara ASEAN dan nilainya jauh di atas nilai impor. Persyaratan terkait tariff measure (TM) meliputi pengkajian otomatis Most Favored Nation (MFN) dan pembuatan regulasi prosedur trade remedies oleh Kemenkes dan Kemendag. Beberapa persyaratan terkait nontariff measure (NTM) seperti implementasi ASEAN Common Technical Dossier (ACTD), implementasi perjanjian pelaksanaan inspeksi Good Manufacturing Pratice, finalisasi dan implementasi perjanjian pelaporan bioekivalensi, finalisasi perjanjian terkait obat tradisional dan suplemen kesehatan sudah dilaksanakan oleh BPOM dan industri. Persyaratan penyederhanaan certificate of origin formulir D, penyederhanaan prosedur sertifikasi operasi dan realisasi sertifikasi mandiri ASEAN masih belum spesifik Kemenkes perlu berkoordinasi dengan BPOM dan Kemendag dalam pembuatan dan pelaksanaan regulasi terkait cetak biru MEA.
\end{abstract}

Kata kunci: Masyarakat Ekonomi ASEAN; Perdagangan bebas barang; Produk farmasi dan alat kesehatan; Cetak biru MEA

\begin{abstract}
The implementation of the ASEAN Economic Community (AEC) as an Indonesian Government's strategic step has an impact on economic globalization. The study on pharmaceutical products and medical devices free trade was done using qualitative and quantitative methods. The data were collected from a round table discussion about "Free Trade in Health Goods and Services in ASEAN" which involved the Ministry of Health (MoH), Ministry of Trade (MoT), and National Agency for Drug and Food Control (NADFC). The discussion aimed to obtain information on the readiness to meet the AEC blueprint. Secondary data on export and import of pharmaceutical products and medical devices were obtained from the MoT. The results of the study show that between 2013 and 2017 there were 70-72 product items exported to 9 ASEAN countries with a value much greater than the import. The tariff measure (TM) requirements included the Most Favored Nation (MFN) assessment and regulation of the trade remedy procedure by $\mathrm{MoH}$ and MoT. The implementation of ASEAN Common Technical Dossier (ACTD) and Good Manufacturing Practice inspection agreements, Bioequivalence reporting agreements, agreements related to traditional medicines and health supplement have been done by NADFC and industry. The simplification of Certificate of Origin, operation certification procedures and realization of ASEAN self-certification have to be specified. MoH must coordinate with NADFC and MoT in deciding and implementing regulations.
\end{abstract}

Keywords: ASEAN Economic Community; Free trade in goods; Pharmaceutical products and medical devices; AEC blueprint 


\section{PENDAHULUAN}

Masyarakat Ekonomi ASEAN (MEA) merupakan bentuk integrasi ekonomi di kawasan ASEAN. MEA bertujuan untuk membentuk kawasan ekonomi yang berdaya saing tinggi dan mendorong terjadi pemerataan pembangunan ekonomi yang terintegrasi ke dalam ekonomi global. Dalam upaya perwujudannya, MEA mengacu pada Cetak Biru Masyarakat Ekonomi ASEAN (AEC Blueprint). Secara umum AEC Blueprint 2025 mempunyai 5 karakteristik, yaitu ekonomi yang terintegrasi dan terpadu, kompetitif, inovatif dan dinamis dengan peningkatan hubungan dan kerjasama sektoral serta terintegrasi dengan ekonomi global. ${ }^{1}$

Sesuai dengan prinsip World Trade Organization (WTO), proses perdagangan bebas barang dan jasa di ASEAN bersifat progresif, yakni setiap negara Anggota ASEAN tidak diperkenankan untuk menarik kembali komitmen yang telah disepakati (no backtracking). Oleh karena itu, hal-hal yang dibahas dalam perdagangan bebas barang adalah penghapusan tarif barang masuk, penghapusan hambatan non tarif, penerapan ketentuan asal barang, fasilitasi perdagangan, integrasi kepabeanan, penerapan ASEAN Single Window (ASW), penyelarasan standar, regulasi teknis dan porsedur penilaian kesesuaian. ${ }^{2}$

Industri farmasi Indonesia saat ini berjumlah 206 industri yang terdiri dari 4 BUMN, 178 industri swasta, dan 24 industri multinasional. ${ }^{3}$ Saat ini kurang lebih $70 \%$ kebutuhan obat sudah dapat diproduksi industri farmasi di dalam negeri walaupun masih sangat tergantung dengan bahan baku impor. Lebih dari $90 \%$ bahan baku yang digunakan diimpor terutama dari China dan India. ${ }^{4}$ Nilai total impor bahan baku farmasi tahun 2014 mencapai Rp. 14,8 triliun. Sumber daya manusia yang ahli dan profesional untuk memproduksi bahan baku obat jumlahnya masih sangat terbatas, keadaan infrastruktur juga masih terbatas, serta belum ada kebijakan kuat dan sistematis yang dapat mengadvokasi, mengendalikan, dan mengarahkan seluruh pemangku kepentingan. ${ }^{4}$

Data perizinan yang diterbitkan oleh Kemenkes, per 30 April 2017 menunjukkan ada pertumbuhan industri alat kesehatan dalam negeri. Jumlah sarana produksi alat kesehatan meningkat dari 202 sarana pada tahun 2015 menjadi 489 dan 615 sarana pada tahun 2016 dan 2017..$^{5}$ Akan tetapi, peningkatan jenis alkes yang diproduksi di Indonesia kurang signifikan karena kebanyakan industri baru cenderung memilih untuk memproduksi jenis alkes yang memiliki pangsa pasar besar di Indonesia meskipun sudah ada pesaingnya.

Implementasi MEA merupakan salah satu langkah strategis yang diambil oleh pemerintah Indonesia dalam memanfaatkan globalisasi ekonomi. Pemberlakuan MEA dapat meningkatkan perdagangan intra-regional serta meningkatkan persaingan untuk mendapatkan investasi, produksi, dan perdagangan di kawasan ASEAN. Posisi sebuah negara pada perdagangan bebas dapat diketahui melalui data sekunder ekspor dan impor. Aktivitas perdagangan berguna untuk mengukur daya saing. Pada umumnya pasar ekspor memiliki tingkat persaingan yang tinggi sehingga secara tidak langsung ekspor juga merupakan indikator efisiensi sektor industri saat menghadapi kompetisi lebih ketat dan lebih intensif. Data perdagangan bebas produk farmasi di lingkup ASEAN penting untuk mengetahui kesiapan Indonesia dalam berkompetisi di tingkat global. Untuk mengantisipasi semakin cepatnya proses perdagangan bebas barang, khususnya produk farmasi dan alat kesehatan, diperlukan data dan kajian kebijakan mengenai perdagangan bebas produk farmasi dan alat kesehatan serta kesiapan memenuhi persyaratan cetak biru MEA. 


\section{METODE}

Penelitian ini merupakan penelitian kualitatif dan kuantitatif yang bertujuan untuk memberikan pemahaman mengenai kesiapan memenuhi persyaratan cetak biru MEA. Secara garis besar dalam konteks perdagangan bebas barang, persyaratan cetak biru MEA adalah Tariff Measure (TM) dan Non-Tariff Measure (NTM). Data diperoleh melalui round table discussion (RTD) dengan peserta mencakup perwakilan dari Kementerian Kesehatan, Kementerian Perdagangan dan Badan Pengawas Obat dan Makanan (BPOM). Dalam RTD dibahas isu mengenai TM terkait kemungkinan penerapan Most Favoured Nation (MFN) otomatis dan peninjauan prosedur trade remedies yang berlaku. Isu terkait NTM adalah ASEAN Common Technical Dossier (ACTD)/ASEAN Common Technical Requirements (ACTR), Mutual Recognition Arrangement (MRA) on Good Manufacturing Pratice (GMP), MRA on Bioequivalence (BE), payung hukum suplemen kesehatan dan obat tradisional, Certificate of Origin (CO), Operation Certification Procedure (OCP), sertifikasi mandiri ASEAN, fasilitasi perdagangan seperti ASEAN Single Window (ASW), ASEAN Trade Repository (ATR), dan ASEAN Solution for Investment, Services and Trade (ASSIST). Data sekunder ekspor dan impor antara 9 negara ASEAN diperoleh dari Kemendag.

\section{HASIL DAN PEMBAHASAN}

\section{Data ekspor dan impor produk farmasi} dan alat kesehatan

Data ekspor dan impor produk farmasi dan alat kesehatan antar 9 negara ASEAN yang diperoleh dari Kementerian Perdagangan mencakup Brunei, Kamboja, Laos, Malaysia, Myanmar, Filipina, Singapura, Thailand, dan Vietnam. Data tersebut berasal dari 99 jenis produk yang pernah diekspor dan atau diimpor oleh Indonesia tahun 2013-2017 (Tabel 1).

Nilai ekspor produk farmasi dan alat kesehatan Indonesia meningkat dari tahun 2013 hingga Agustus 2017 sedangkan nilai impor mengikuti pola gergaji (naik-turun). Perbandingan nilai ekspor terhadap impor menunjukkan nilai yang naik, yaitu nilai ekspor 2,35 kali hingga 3,2 kali dari nilai impor.

Data ekspor menunjukkan bahwa 9 negara ASEAN setiap tahun melakukan impor produk farmasi dan alat kesehatan dari Indonesia (Tabel 2), terutama Singapura, Filipina, dan Thailand. Ini menandakan produk farmasi dan alat kesehatan Indonesia bisa diterima di semua Negara ASEAN. Setiap tahun dari tahun 2013 sampai 2017 terdapat 70 - 72 item produk yang diekspor.

Tabel 1. Nilai ekspor dan impor Indonesia tahun 2013-Agustus 2017

\begin{tabular}{rrrrccc}
\hline \multirow{2}{*}{ No } & Keterangan & $\mathbf{2 0 1 3}$ & $\mathbf{2 0 1 4}$ & $\mathbf{2 0 1 5}$ & $\mathbf{2 0 1 6}$ & $\begin{array}{c}\mathbf{2 0 1 7} \text { (s/d } \\
\text { Agustus) }\end{array}$ \\
\cline { 3 - 7 } & & & & & & \\
1 & Ekspor (USD) & 163.628 .057 & 196.600 .114 & 246.546 .713 & 287.176 .639 & 209.186 .542 \\
2 & Impor (USD) & 69.515 .716 & 84.585 .118 & 97.918 .636 & 93.612 .304 & 65.327 .616 \\
\hline
\end{tabular}


Tabel 2. Total prosentase ekspor produk farmasi dan alat kesehatan ke ASEAN

\begin{tabular}{|c|c|c|c|c|c|c|}
\hline \multirow[b]{2}{*}{ No } & \multirow[b]{2}{*}{ Negara } & \multicolumn{5}{|c|}{ Total prosentase ekspor } \\
\hline & & 2013 & 2014 & 2015 & 2016 & $\begin{array}{l}2017(\mathrm{~s} / \mathrm{d} \\
\text { agustus) }\end{array}$ \\
\hline 1 & Brunei & 0,29 & 0,29 & 0,18 & 0,15 & 0,16 \\
\hline 2 & Kamboja & 4,11 & 3,49 & 3,5 & 3,04 & 2,71 \\
\hline 3 & Laos & 0,01 & 0,08 & 0,03 & 0,04 & 0,03 \\
\hline 4 & Malaysia & 9,79 & 7,26 & 15,66 & 10,84 & 6,33 \\
\hline 5 & Myanmar & 7,72 & 9,69 & 8,51 & 7,21 & 6,39 \\
\hline 6 & Filipina & 35,32 & 35,22 & 31,31 & 24,97 & 24,38 \\
\hline 7 & Singapura & 6,7 & 7,42 & 11,17 & 23,58 & 36,96 \\
\hline 8 & Thailand & 22,98 & 24,23 & 23,6 & 22,02 & 15,69 \\
\hline 9 & Vietnam & 13,08 & 12,32 & 6,04 & 8,15 & 7,35 \\
\hline
\end{tabular}

Tabel 3. Total prosentase ekspor produk farmasi dan alat kesehatan $\geq 1 \%$

\begin{tabular}{|c|c|c|c|c|c|c|}
\hline \multirow[b]{2}{*}{ No } & \multirow[b]{2}{*}{ HS Code } & \multicolumn{5}{|c|}{ Prosentase ekspor $\geq 1 \%$} \\
\hline & & 2013 & 2014 & 2015 & 2016 & $\begin{array}{l}2017 \text { (s/d } \\
\text { Agustus) }\end{array}$ \\
\hline 1 & 3002.20 .90 .10 & & & & 1,04 & 1,4 \\
\hline 2 & 3002.30 .00 .00 & & & 1,91 & 3,28 & 4,8 \\
\hline 3 & 3003.10 .20 .00 & 1,79 & & 2,3 & 2,16 & \\
\hline 4 & 3003.20 .00 .00 & 2,58 & 2,08 & 2,12 & 2,13 & 1,8 \\
\hline 5 & 3004.10 .16 .00 & 1,38 & 1,96 & 1,02 & & \\
\hline 6 & 3004.10 .21 .00 & & 1,82 & 18,36 & 3,98 & \\
\hline 7 & 3004.10 .29 .00 & 26,22 & 31,98 & 16,03 & 27,32 & 28,8 \\
\hline 8 & 3004.20 .79 .00 & 1,87 & & & & \\
\hline 9 & 3004.50 .91 .00 & 5,32 & 2,97 & & & \\
\hline 10 & 3004.90 .30 .00 & & & & 2,17 & 2,1 \\
\hline 11 & 3004.90 .59 .10 & 1,49 & 2,29 & 1,96 & 1,01 & \\
\hline 12 & 3004.90 .81 .00 & & & 2,42 & 4,48 & 3 \\
\hline 13 & 3004.90 .82 .00 & & & 1,14 & 1,66 & \\
\hline 14 & 3004.90 .94 .00 & 3,01 & 2 & 1,28 & 1,17 & \\
\hline 15 & 3004.90 .95 .00 & 6,15 & 4,24 & 3,81 & 1,69 & 1,9 \\
\hline 16 & 3004.90 .98 .00 & & & 2,46 & 3,61 & 6,1 \\
\hline 17 & 3005.90 .10 .00 & 1,11 & 1,34 & 1,32 & 4,25 & 5,5 \\
\hline 18 & 3006.10 .10 .00 & 21,46 & 21,42 & 11,9 & 5,19 & 4,8 \\
\hline 19 & 3006.30 .20 .00 & & & & 1,93 & 3,1 \\
\hline 20 & 3006.40 .10 .00 & & & & 1,08 & 1,2 \\
\hline 21 & 3006.60 .00 .00 & 9,85 & 6,68 & 5,18 & 5,42 & 7,1 \\
\hline 22 & 3006.70 .00 .00 & & & 1,42 & & \\
\hline 23 & 3504.00 .00 .00 & 1,77 & 2,25 & 2,01 & 1,84 & 1,6 \\
\hline 24 & 3507.10 .00 .00 & 7 & 5,99 & 13,02 & 15,52 & 15,3 \\
\hline & Total & 91 & 87,02 & 89,66 & 90,93 & 88,5 \\
\hline
\end{tabular}


Harmonized System (HS) Code adalah kode nomor yang tersusun sistematik dalam mengklasifikasikan produk perdagangan dan disepakati secara internasional. Indonesia menggunakan sistem penomoran 10-digit dalam Buku Tarif Bea Masuk Indonesia (BTBMI). Lima produk utama yang secara konstan di ekspor ke Negara ASEAN dari tahun 2013-Agustus 2017 adalah HS code: 3004.10.29.00;3006.10.10.00;3507.10.00. 00;3006.60.00.00;3004.90.94.00 (Tabel 3).

Terdapat 5-6 negara ASEAN setiap tahun mengekspor produk farmasi dan alat kesehatan ke Indonesia. Dari tahun 20132017 nilai impor produk mempunyai kecenderungan tidak berpola. Mayoritas produk impor berturut-turut berasal dari Singapura, Thailand dan Malaysia (Tabel 4).

Thailand dan Singapura merupakan negara yang rutin melakukan ekspor produknya ke Indonesia. Dua negara ASEAN yang tidak pernah mengekspor produknya ke Indonesia adalah Kamboja dan Laos. Setiap tahun dari tahun 2013 sampai 2017 terdapat 59 - 64 item produk yang diimpor oleh Indonesia. Ada 21 produk dengan nilai impor lebih dari $1 \%$
(Tabel 5). HS Code 5 jenis produk yang paling banyak di impor oleh Indonesia dari tahun 2013-Agustus 2017 adalah 3004.90.99.00;2936.90.00.00;3004.90.82. 00;3004.90.91.00; dan 3507.90.00.00.

Perbandingan nilai ekspor terhadap impor menunjukkan nilai yang naik, yaitu nilai ekspor 2,35 kali hingga 3,2 kali dari nilai impor. Hal ini sejalan dengan penelitian yang dilakukan oleh Elsa Yufani dan Syafri Harto yang menyimpulkan nilai perdagangan Indonesia dengan negara intra-ASEAN terutama Singapura semakin meningkat. ${ }^{6}$ Kajian oleh Arianti, dkk tahun 2010 yang bertajuk "Kinerja Perdagangan serta Strategi Ekspor Produk-produk Pharmaceutical dan Kosmetik Berbasis Herbal Indonesia di Pasar Dunia" juga menunjukkan Indonesia merupakan pemasok utama bahan baku kosmetik berbasis herbal di pasar dunia dengan pangsa 13 persen pada tahun 2007, sementara untuk bahan baku farmasi Indonesia memasok 2 persen (peringkat 16 dunia). Sebagai pemasok produk farmasi herbal, Indonesia berada di urutan ke-54 dunia, sedangkan untuk produk kosmetik herbal Indonesia menduduki posisi ke-28 di dunia. ${ }^{7}$

Tabel 4. Total prosentase impor produk farmasi dan alat kesehatan ke ASEAN

\begin{tabular}{llrrrrr}
\hline & & \multicolumn{6}{c}{ Total prosentase impor } \\
\cline { 3 - 7 } No & Negara & $\mathbf{2 0 1 3}$ & $\mathbf{2 0 1 4}$ & $\mathbf{2 0 1 5}$ & $\mathbf{2 0 1 6}$ & $\begin{array}{r}\mathbf{2 0 1 7}(\mathbf{s} / \mathbf{d} \\
\text { Agustus) }\end{array}$ \\
\hline 1 & Brunei & 0 & 0,09 & 0,02 & 0 & 0 \\
2 & Kamboja & 0 & 0 & 0,00 & 0 & 0 \\
3 & Laos & 0 & 0 & 0,00 & 0 & 0 \\
4 & Malaysia & 27,94 & 0 & 20,51 & 21,47 & 17,37 \\
5 & Myanmar & 0 & 24,9 & 0,00 & 0 & 0 \\
6 & Filipina & 0,52 & 0 & 0,06 & 0,11 & 0,37 \\
7 & Singapura & 54,37 & 0,45 & 61,81 & 63,37 & 68,71 \\
8 & Thailand & 17,07 & 62,4 & 17,42 & 14,92 & 12,63 \\
9 & Vietnam & 0,1 & 12,17 & 0,17 & 0,14 & 0,92 \\
\hline
\end{tabular}


Tabel 5. Total Prosentase Impor Produk Farmasi dan Alat Kesehatan $\geq 1 \%$

\begin{tabular}{|c|c|c|c|c|c|c|}
\hline \multirow{2}{*}{ No } & \multirow{2}{*}{ HS Code } & \multicolumn{2}{|c|}{$\begin{array}{c}\text { Prosentase } \\
\text { Impor } \geq 1 \%\end{array}$} & \multirow[b]{2}{*}{2015} & \multirow[b]{2}{*}{2016} & \multirow[b]{2}{*}{$\begin{array}{l}2017 \text { (s/d } \\
\text { Agustus) }\end{array}$} \\
\hline & & 2013 & 2014 & & & \\
\hline 1 & 2936.28 .00 .00 & 1,67 & 1,65 & & & 1,5 \\
\hline 2 & 2936.29.00.00 & 3,28 & & & & \\
\hline 3 & 2936.90 .00 .00 & 27,86 & 25,73 & 22,43 & 19,63 & 8,25 \\
\hline 4 & 2941.50 .00 .00 & 2,68 & & & & \\
\hline 5 & 3002.30 .00 .00 & 1,32 & & & & \\
\hline 6 & 3004.20 .99 .00 & 3,11 & 2,86 & 3,04 & 1,26 & 2,25 \\
\hline 7 & 3004.39 .00 .00 & 10,48 & & 1,81 & 2,42 & 3,6 \\
\hline 8 & 3004.50 .99 .00 & 2,28 & 1,97 & 2,24 & 1,31 & 1,97 \\
\hline 9 & 3004.90 .10 .00 & & 7,56 & & & \\
\hline 10 & 3004.90 .30 .00 & 1,11 & & & & \\
\hline 11 & 3004.90 .59 .10 & & 1,15 & & & \\
\hline 12 & 3004.90 .59 .90 & & 1,15 & & & \\
\hline 13 & 3004.90 .82 .00 & & 3,79 & 26,74 & 23,9 & 25,06 \\
\hline 14 & 3004.90 .91 .00 & 6,19 & 5,88 & 4,2 & 9,21 & 9,56 \\
\hline 15 & 3004.90 .98 .00 & & & & 3,12 & 5,07 \\
\hline 16 & 3004.90 .99 .00 & 17,81 & 29,97 & 26,47 & 25,3 & 24,52 \\
\hline 17 & 3006.10 .10 .00 & 4,93 & 2,83 & & 1,68 & 3,18 \\
\hline 18 & 3006.10 .90 .00 & 1,63 & 1,21 & 1,14 & 1,68 & 2,11 \\
\hline 19 & 3006.30 .20 .00 & & 1,28 & & & \\
\hline 20 & 3006.70 .00 .00 & 1,91 & & & & \\
\hline 21 & 3507.90 .00 .00 & 5 & 1,95 & 3,31 & 3,52 & 5,36 \\
\hline & Total & 91,26 & 88,98 & 91,38 & 93,03 & 92,43 \\
\hline
\end{tabular}

Produk farmasi Indonesia dapat diterima olehi semua negara anggota ASEAN karena standar industri farmasi Indonesia telah diakui. Direktur Eksekutif Gabungan Pengusaha Farmasi Indonesia Dorodjatun Sanusi mengatakan meskipun industri farmasi lokal sejatinya sudah lama melakukan penetrasi pasar di ASEAN, masih ada 3 negara yang belum yaitu Thailand, Brunei dan Laos. ${ }^{8}$ Hal ini tidak berdampak terhadap kenaikan nilai ekspor produk farmasi Indonesia pasca penetapan kerjasama Masyarakat Ekonomi ASEAN.

Thailand belum menjadi anggota PIC/S dan ini akan berpengaruh terhadap standar kualitas produk farmasi yang dihasilkannya, namun menurut pendapat Dorodjatun Sanusi secara umum kondisi
Industri Farmasi ASEAN dapat dikatakan berada pada posisi yang hampir sama (same level of playing field). ${ }^{9}$

Daya saing produk farmasi dan alat kesehatan suatu negara dipengaruhi oleh banyak faktor. Dalam penelitian ini hanya membahas faktor terkait aktivitas perdagangan bebas. Secara garis besar ada 2 pembahasan yang berhubungan dengan perdagangan bebas yaitu terkait TM dan NTM.

Hasil RTD terkait penerapan otomatis MFN adalah tarif yang dikenakan terhadap bahan baku farmasi antara $0 \%-5 \%$ dan hanya beberapa jenis yang masih dikenakan tarif tinggi. RTD juga mendiskusikan kemungkinan penerapan otomatis MFN untuk bea masuk belum 
masuk dalam renstra Kemenkes tahun 2015-2019. Selain itu, sampai saat ini penyusunan tarif di BTKI untuk produk farmasi belum berkoordinasi dengan Kementerian Kesehatan. Oleh karena itu, Kemenkes perlu melakukan diskusi terkait implementasi otomatis MFN ini, terutama dengan BPOM dan Ditjen Bea dan Cukai, yakni perubahan tarif pada BTKI untuk sediaan farmasi. Sampai tahun 2025, penerapan otomatis MFN perlu dikaji kembali terutama terkait perubahan tarif sediaan farmasi karena sediaan farmasi sering terdiri dari beberapa produk inovatif yang diperoleh melalui impor hingga sangat rentan. Strategi inisiasi koordinasi penetapan tarif dalam BTKI dengan Kemenkes dibutuhkan agar Kemenkes dapat memitigasi perubahan tarif sediaan farmasi impor dan ekspor. Hal ini sangat diperlukan agar produk farmasi terutama produk sensitif atau produk lokal yang perlu diproteksi melalui kendali tarif lebih terjamin saat tarif impor turun/naik. Untuk itu, dibutuhkan kajian penerapan otomatis MFN terkait tarif sediaan farmasi.

Kemenkes berperan memberikan masukan dalam penyusunan BTKI meskipun peraturan ini ditetapkan oleh Menteri Keuangan. Hal ini sesuai dengan penelitian yang dilakukan oleh Sari, dkk yaitu Bea Masuk merupakan pungutan negara untuk barang impor yang harus dibayarkan pada saat barang diimpor untuk dipakai atau sesuai dengan ketentuan Menteri Keuangan. ${ }^{10}$

Renstra Kemenkes 2015-2019 belum membahas kemungkinan peninjauan terhadap prosedur trade remedies di negara anggota ASEAN (AMS/ASEAN Member States) dan memantapkan persyaratan notifikasi. Pemerintah saat ini mendorong agar industri farmasi memproduksi bahan baku obat di dalam negeri guna mengurangi ketergantungan impor agar trade remedies bisa dilakukan. Meskipun sediaan jadi farmasi sebagian besar sudah dipenuhi oleh produksi dalam negeri, bila produk jadi ASEAN juga sudah dapat masuk ke Indonesia, perlu antisipasi terkait mekanisme trade remedies ini ketika pasar dalam negeri sudah mendekati jenuh. Mekanisme e-catalog dan e-purchasing diharapkan dapat mendorong penggunaan produk lokal dalam situasi pasar yang telah jenuh. Selain itu, inisiasi dan dukungan untuk produksi sediaan farmasi yang inovatif di lingkup lokal sangat diperlukan. Perlu ada workshop tentang produksi sediaan farmasi termasuk riset dan hasilnya serta rencana pengembangan yang akan datang.

Penelitian oleh Alhayat menyimpulkan bahwa bila pemerintah ingin menurunkan laju impor maka diperlukan instrumen kebijakan selain tindakan pengamanan perdagangan (trade remedies) yang lebih efektif dan bersifat jangka panjang. Pengendalian impor dapat diarahkan kepada hal-hal yang sifatnya bukan tarif, seperti persyaratan keamanan, sanitasi dan standardisasi. ${ }^{11}$

Badan POM telah memiliki kebijakan terkait NTM. ACTD telah diterapkan oleh BPOM dalam inspeksi maupun penilaian pengajuan nomor izin edar (NIE) yang sesuai dengan kebijakan PICs (Pharmaceutical Inspection Scheme), optimasi ACTD dibutuhkan untuk mempercepat penetrasi pasar sediaan farmasi Indonesia ke pasar ASEAN. Sampai tahun 2025 beberapa kebijakan non-tarif seperti ACTD ini masih diperlakukan berbeda pada beberapa negara, misalnya Vietnam yang mensyaratkan juga sertifikat GMP FDA untuk impornya. Oleh karena itu perlu koordinasi penerapan MRA dan ACTD secara menyeluruh sebagai persyaratan ekspansi pasar sediaan farmasi ke ASEAN. Hal ini sesuai dengan penelitian Dinasari, dkk yang menyatakan dengan deklarasi AEC berarti ASEAN Single Window merupakan reformasi dari rules of origin, memberikan pengaruh positif arus barang bebas sehingga Indonesia sendiri membangun Indonesia Single Window yang merupakan National Single Window dengan tujuan untuk kelancaran 
perdagangan ekspor-impor pada lingkup regional. $^{12}$

Implementasi MRA on Good Manufacturing Pratice (GMP) dan on Bioequivalence (BE) belum diatur oleh Renstra Kemenkes hingga tahun 2019. Walaupun demikian, BPOM telah menginisiasi dan memiliki kebijakan dalam pengaturan GMP dan melakukan supervisi pengujian BE yang dilaksanakan oleh Clinical Research Organizations (CROs) terlatih dan Kemenkes juga telah mendapatkan pelatihan MRA. Meskipun BPOM dan Kemenkes telah menginisiasi penerapan MRA GMP dan MRA BE Study Report, masih terdapat perbedaan penerapannya di negara ASEAN, terutama mengenai implementasi MRA.

Industri farmasi dan alat kesehatan Indonesia sudah mengikuti standar internasional dan ASEAN dan dalam hal jumlah sudah cukup untuk memenuhi kebutuhan dalam negeri. Hal ini tidak sejalan dengan hasil penelitian Saragih yang menyatakan lemahnya posisi tawar Indonesia terutama disebabkan oleh tidak adanya strategi dan kebijakan industri yang komprehensif yang akan menjadi referensi bagi pemerintah. Strategi dan kebijakan industrialisasi nasional ini pula yang kemudian akan menjadi acuan bagi kesepakatan pemangkasan tarif bea masuk membuka atau membatasi impor suatu produk. $^{13}$

Indonesia sudah terdaftar sebagai anggota PIC/S melalui Keputusan Presiden Nomor 35 Tahun 2012. Semua inspektor dari BPOM telah terlatih $\mathrm{PIC} / \mathrm{S}$ dalam inspeksi ke industri farmasi sesuai standar $\mathrm{PIC} / \mathrm{S}$. Industri farmasi di Indonesia telah mengikuti standar CPOB yang diperbaharui setiap 5 tahun di bawah pengawasan inspektor BPOM. Hal ini sesuai dengan hasil penelitian Darmawan dan Irawan yang menyatakan agar suatu sediaan blood product dapat terjamin mutu, keamanan dan efikasinya maka pada setiap tahap prosesnya harus konsisten berpedoman $\mathrm{CPOB}$ yang sesuai dengan standar WHO. $^{14}$ Sementara itu, PIC/S
GMP Guide for Blood Establishments (July, 2004) merupakan salah satu buku panduan CPOB untuk produk darah yang disusun oleh tim PIC/S.

Implementasi perjanjian kerjasama pelaporan studi bioekivalensi terkendala karena berkaitan dengan kesiapan negara anggota ASEAN dalam melakukan studi bioekivalensi. Indonesia merupakan negara anggota ASEAN yang mempunyai laboratorium BA/BE (Bioavailability/ Bioequivalence) terbanyak yaitu 12 laboratorium aktif. Hal ini sejalan dengan penelitian Rachmawati, dkk yang menyatakan bahwa persyaratan uji BA/BE bagi produk obat copy penting dalam rangka penjaminan mutu dan efektivitas obat, serta peningkatan daya saing global. Kewajiban uji BA/BE bagi produsen perlu diberlakukan sebagai upaya penjaminan mutu obat oleh pemerintah. Pedoman uji BA/BE yang telah dikeluarkan BPOM bisa menjadi acuan bagi produsen obat copy. ${ }^{15}$

Pelaksanaan notifikasi perjanjian terkait obat tradisional (OT) dan suplemen kesehatan tidak diatur dalam renstra Kementerian Kesehatan sampai 2019. Pelaksanaan notifikasi ini merupakan fokal point di BPOM dengan optimalisasi peningkatan nilai tambah produksi dalam negeri, di antaranya koordinasi teknis penajaman fisibilitas kerjasama ekspansi OT dan suplemen kesehatan ke negara ASEAN.

Penyederhanaan CO form D oleh Kemenkes dengan implementasi sistem elektronik dalam penerbitan izin impor dengan $\mathrm{CO}$ (Certificate of Origin) yang dapat diunggah melalui sistem tersebut. Hal ini untuk memudahkan pemohon melaksanakan import dan memudahkan pemerintah mengendalikan pemasukan ke dalam wilayah Indonesia. Akan tetapi, penyederhaan form $D$ yang spesifik untuk sediaan farmasi belum diatur. Selain untuk memastikan asal dari produk (termasuk bahan baku), form $\mathrm{D}$ sangat menentukan ketertelusuran produk farmasi yang diimpor mengingat akan diberlakukan label ASEAN di masa datang. Kemenkes 
perlu melakukan koordinasi teknis penajaman terkait pemberlakuan $\mathrm{CO}$ dalam Form D bersama BPOM dan Ditjen Bea Cukai untuk antisipasi mobilitas barang yang meningkat.

Prosedur Sertifikasi Operasi (OCP) tidak diatur dalam Renstra Kementerian Kesehatan, namun dalam dokumen impor ekspor pemohon diminta untuk menginisiasi implementasi OCP. Pelayanan impor/ekspor sediaan farmasi telah dilakukan secara online termasuk pembayaran PNBP melalui e-Payment. Kementerian Perdagangan telah menerbitkan ketentuan mengenai OCP tetapi dalam praktik tidak berhubungan dengan impor ekpor sediaan farmasi. Oleh karena itu, perlu penajaman prosedur OCP terkait penerapan sertifikasi OCP ini, terutama implementasi teknis di lapangan dan mitigasi yang diperlukan. Saat ini industri farmasi belum terpapar kebijakan dan mekanisme sertifikasi OCP ini, termasuk mitigasi yang harus dipersiapkan. Perlu pengkajian dan pemetaan mengenai hal-hal terkait teknis implementasi sertifikasi OCP.

Kementerian Perdagangan telah menerbitkan ketentuan mengenai Sertifikasi Mandiri ASEAN dalam dokumen ekspor impor, namun Renstra Kemenkes hingga tahun 2019 tidak mengatur hal ini. Penjajakan terkait mekanisme sertifikasi mandiri ini dalam bidang farmasi yang perlu disikapi melalui koordinasi teknis penajaman terkait pemberlakuan sertifikasi mandiri ASEAN.

Fasilitasi platform perdagangan sudah ada seperti ASW, ATR, dan ASSIST, Kemenkes telah mendorong pelaku bisnis kefarmasian seperti Industri farmasi, kosmetik dan obat tradisional untuk menginisiasi penyelesaian masalah terkait impor ekspor melalui ASW, ATR dan ASSIST. Beberapa industri kefarmasian yang mengalami kendala terkait non-tarif barrier telah mencoba melalui ASSIST. Akan tetapi masih belum diketahui sejauh mana dampak penggunaan platform ASW, ATR, dan ASSIST. Kebutuhan koordinasi teknis dan asistensi dari pemerintah terhadap pelaku usaha yang menghadapi kendala diperlukan agar diketahui secara pasti dampak penggunaan platform ini dalam penyelesaian kendala tersebut.

BPOM merupakan HOD (Head of Delegate) Indonesia yang bertugas menangani harmonisasi ASEAN bidang obat tradisional dan suplemen kesehatan. Tujuan harmonisasi adalah meningkatkan kerjasama antar negara ASEAN untuk menjamin keamanan, mutu dan khasiat obat tradisional dan suplemen kesehatan serta memfasilitasi perdagangannya. Harmonisasi dilakukan terhadap standar/persyaratan/pedoman. Harmonisasi sudah dimulai sejak tahun 2004 dan menghasilkan ASEAN guideline negative list tumbuhan yang dibolehkan, pedoman tentang additif dan eksipien, GMP, serta batas kontaminan. Pedoman ini yang harus diimplementasikan oleh negara anggota ASEAN yang melakukan perdagangan bebas barang ke negara ASEAN lainnya.

Setiap negara anggota ASEAN mempunyai regulasi NTM masing-masing sehingga tidak mudah diharmonisasikan. Perlu upaya Kemenkes dan industri terkait untuk mengorganisir NTM dari tiap negara tersebut. Hal ini sesuai dengan penelitian yang dilakukan Dahar, dkk yang menyatakan bahwa sanitary and phytosanitary (SPS) dan technical barriers to trade (TBT) yang dikenakan oleh Negara ASEAN+3 (Negara ASEAN + Tiongkok, Jepang dan Korea Selatan) terutama Jepang pada seluruh produk hortikultura diberlakukan. Dari keempat kelompok hortikultura yang paling banyak terkena NTM adalah kelompok sayuran. NTM yang digunakan pada negara ASEAN+3 lebih banyak adalah SPS. Singapura merupakan negara yang tidak memberlakukan SPS dan TBT. ${ }^{13}$ Penelitian lain yang juga sejalan dilakukan oleh Sari, dkk yang menyatakan jenis NTM yang digunakan yaitu SPS, TBT dan trade remedy (antidumping, subsidy, safeguard). Negara pengimpor utama yang paling banyak mengenakan NTM adalah Amerika 
Serikat, dan kebijakan TBT lebih banyak diterapkan oleh negara pengimpor utamanya. Secara keseluruhan NTM dari negara tujuan ekspor menghambat arus perdagangan ekspor komoditi CPO Indonesia, tetapi pengaruhnya tidak nyata. Jika NTM diuraikan berdasarkan jenisnya yaitu SPS, TBT dan TR, hasilnya menunjukkan bahwa pengaruh NTM pada kebijakan SPS signifikan 5\% dengan koefisien bernilai positif yaitu 0,34, sedangkan kebijakan TBT signifikan 1\% dengan nilai koefisien -0,41 dan kebijakan TR juga signifikan $1 \%$ dengan koefisien 1,41 . Oleh karena itu, kebijakan yang lebih dominan menghambat arus perdagangan ekspor komoditi CPO Indonesia adalah kebijakan TBT. ${ }^{10}$

Standardisasi masuk dalam kategori hambatan non tarif (nontariff barrier) yang dianggap sebagai upaya negara untuk melindungi kepentingan ekonomi domestiknya terhadap produk impor. Hal ini sejalan dengan hasil penelitian yang dilakukan oleh Alhayat yang menyatakan bahwa pengendalian impor dapat diarahkan kepada hal yang sifatnya bukan tarif, seperti persyaratan keamanan, sanitasi dan standarisasi. Hal ini dikarenakan tambahan pengenaan tarif melalui BMAD (Bea Masuk Anti Dumping) hanya memberikan dampak yang relatif kecil terhadap penurunan impor. ${ }^{11}$ Kajian mengenai hambatan non tarif mengenai kebijakan standardisasi hingga saat ini sering dilakukan karena pengaruhnya pada penurunan angka ekspor bagi beberapa negara anggota WTO, khususnya negara berkembang, yang kesulitan memenuhi tingginya standardisasi pasar internasional. Standardisasi internasional memang diperlukan selama disepakati dan memungkinkan untuk dapat dipenuhi oleh negara anggota WTO lainnya. Sebaliknya, jika standar terlalu tinggi justru akan menghambat kegiatan perdagangan internasional suatu negara.

Tujuan regulasi standardisasi ini adalah sebagai unsur penunjang pembangunan, yaitu optimalisasi pendayagunaan sumber daya, penunjang kemampuan produksi khususnya peningkatan perdagangan internasional, serta pengembangan industri dan perlindungan konsumen. Indonesia yang yang turut meratifikasi kerangka WTO harus tunduk pada aturan kesepakatan tersebut dan menyesuaikan peraturan perundang-undangannya dengan kerangka atau regulasi yang dikeluarkan oleh WTO. ${ }^{14}$

Sejauh ini ada dua regulasi terkait TM yang dikeluarkan oleh Indonesia yaitu Peraturan Pemerintah No. 44 Tahun 2014 tentang Daftar Bidang Usaha yang Tertutup dan Bidang Usaha yang Terbuka dengan Persyaratan di Bidang Penanaman Modal (Lembaran Negara Republik Indonesia Tahun 2016 Nomor 97) dan Peraturan Menteri Keuangan No. 25/PMK.010/2017 tentang Penerapan Tarif Bea Masuk ASEAN Trade in Goods Agreement (Berita Negara Republik Indonesia Tahun 2017 Nomor 341) yang mengatur prosentase investasi asing sebagai syarat pendirian suatu industri farmasi asing di Indonesia dan tarif produk sesuai kesepatakan ATIGA.

Selain itu, banyak regulasi terkait NTM yang dikeluarkan oleh Indonesia, yaitu Undang-Undang No. 20 Tahun 2014 tentang Standardisasi dan Penilaian Kesesuaian, Peraturan Pemerintah No. 14 Tahun 2015 tentang Rencana Induk Pembangunan Industri Nasional 20152035 (Lembaran Negara Republik Indonesia Tahun 2015 Nomor 46, Tambahan Lembaran Negara Republik Indonesia Nomor 5671), Instruksi Presiden Republik Indonesia No. 6 Tahun 2016 tentang Percepatan Pengembangan Industri Farmasi dan Alat Kesehatan, Permenkes No 10 Tahun 2013 tentang Impor dan Ekspor Narkotik, Psikotropik dan Prekusor Farmasi. Umumnya regulasi yang dikeluarkan oleh Kemenkes di atas masih kurang membahas perdagangan bebas dalam kerangka MEA. 


\section{KESIMPULAN}

Kemenkes harus berperan dalam sosialisasi ke industri terkait cetak biru MEA agar berdampak terhadap kenaikan nilai ekspor. Penerapan otomatis MFN masih belum siap karena belum ada koordinasi antara Kementerian Perdagangan dan Kementerian Kesehatan. Implementasi penyederhanaan $\mathrm{CO}$ formulir D oleh Kemenkes belum diatur untuk sediaan farmasi belum. Realisasi sertifikasi mandiri ASEAN sudah diterbitkan oleh Kementerian Perdagangan pada dokumen ekspor impor tetapi hal ini belum spesifik mencantumkan mengenai mekanisme sertifikasi mandiri bidang farmasi. Peninjauan prosedur trade remedies di negara Anggota ASEAN dan pemantapan persyaratan notifikasi juga belum sepenuhnya dilakukan oleh Kementerian Kesehatan.

\section{UCAPAN TERIMA KASIH}

Ucapan terima kasih disampaikan kepada Pusat Penelitian dan Pengembangan Humaniora dan Manajemen Kesehatan yang telah mendanai kegiatan ini serta para peneliti yang terlibat dalam penyusunan tulisan ini.

\section{DAFTAR RUJUKAN}

1. The ASEAN Secretariat. ASEAN economic community blueprint 2025 [internet]. Jakarta: The ASEAN Secretariat; 2015 Nov [cited 2019 Mar]. Available from: https://www.asean.org/storage/2016/03/A ECBP_2025r_FINAL.pdf

2. The ASEAN Secretariat. ASEAN trade in goods agreement [internet]. Cha-am: The ASEAN Secretariat; 2009 Feb 26 [cited 2019 Mar 3]. Available from: https://www.asean.

org/wpcontent/uploads/images/2012/Econ omic/AFTA/annex/ASEAN\%20Trade $\% 2$ 0in\%20Goods\%20Agreement, \%20Chaam ,\%20Thailand,\%2026\%20February\%2020 09.pdf

3. Republik Indonesia. Peraturan Menteri Kesehatan Nomor 17 Tahun 2017 tentang Rencana Aksi Pengembangan Industri
Farmasi dan Alat Kesehatan, Jakarta: Kementerian Kesehatan; 2017.

4. Ardiyani, Ginting B, Nugraheni T, Sahara $\mathrm{N}$, Yolandra R, et al, Upaya Kemandirian Produksi Bahan Baku Obat Indonesia. Buletin Infarkes. Edisi II Maret - April 2016

http://binfar.kemkes.go.id/?wpdmact=pro cess\&did=MzU1LmhvdGxpbms $=[$ disitasi Mei 2019], 802, 3-6.

5. Primadi O. Jumlah Alat Kesehatan Produksi Dalam Negeri Meningkat, http://sehatnegeriku.kemkes.go.id/baca/ril ismedia/20171109/1723731/jumlah-alatkesehatan-produksi-negeri-meningkat/ [disitasi 10 Febr 2019]

6. Yufani E, Harto S. Implikasi ASEAN economic community blueprint terhadap perkembangan perdagangan Indonesia ke Singapura. Jurnal Online Mahasiswa Bidang Ilmu Sosial dan Ilmu Politik [internet]. 2014 Jun 17 [disitasi 2019 Feb];1(1):1-15.

7. Arianti RK, Hasni H. Kinerja perdagangan serta strategi ekspor produkproduk pharmaceutical dan kosmetik berbasis herbal Indonesia di pasar dunia. Buletin Ilmiah Litbang Perdagangan. 2010 Jul 31;4(1):14-30. https://doi.org/10.30908/bilp.v4i1.149

8. Eeyore. Unggul di produksi obat, kalah di tenaga kerja ahli [internet]. Jakarta: Utama Consulting Business \& Tax Advisory; 2016 Jan 15 [disitasi 10 Febr 2019]. Diunduh dari: https://pemeriksaanpajak.com/2016/01/15 /unggul-di-produksi-obat-kalah-di-tenagakerja-ahli/

9. Khamdi M. MEA 2015: Farmasi Indonesia bersaing ketat dengan Vietnam. Berita Online Ekonomi Bisnis.com [internet]. 2014 Apr 17 [disitasi 2019 Feb 10]. Diunduh dari: https://ekonomi.bisnis.com/read/2014041 7/103/220100/mea-2015-farmasiindonesia-bersaing-ketat-dengan-vietnam

10. Sari TIP, Hidayat K, Setyawan A. Pengaruh bea masuk dan pajak dalam rangka impor (BM dan PDRI) terhadap total penerimaan. Jurnal Perpajakan (JEJAK). 2016;10(1):1-8.

11. Alhayat AP. Efektivitas tindakan anti dumping Indonesia 1996-2010. Buletin Ilmiah Litbang Perdagangan. 2014 Des 31;8(2):247-68. DOI: 
https://doi.org/10.30908/bilp.v8i2.95

12. Dinasari D, Widhiyanti HN, Ikaningtyas I. Kesesuaian aturan multilateral agreement on trade in goods WTO Dengan ATIGA (ASEAN trade in goods agreement). Jurnal Hukum [internet]. 2014 April:1-21.

13. Saragih HM. Indonesia dan persaingan di era ASEAN economic community. Jurnal Masharif Al-Syariah: Jurnal Ekonomi dan Perbankan Syariah. 2017;2(2):117-152. DOI: http://dx.doi.org/10.30651/jms.v2i2.
1445

14. Darmawan A, Irawan R. Mengenal CPOB untuk produk darah. Jambi Medical Journal: Jurnal Kedokteran dan Kesehatan. $2015 \quad$ Nov;3(2):111-18. DOI: https://doi.org/10.22437/jmj.v3i2.30 87

15. Rachmawati E, Holidah D. Uji bioavailabilitas dan bioekuivalensi obat: urgensi dan pedoman pelaksanaannya. Saintifika. 2011 Jun;13(1):91-7. 